\title{
Balloon-assisted endoscopic extraction of a lamp bulb stuck in the rectosigmoid junction: an inspiration from ERCP
}

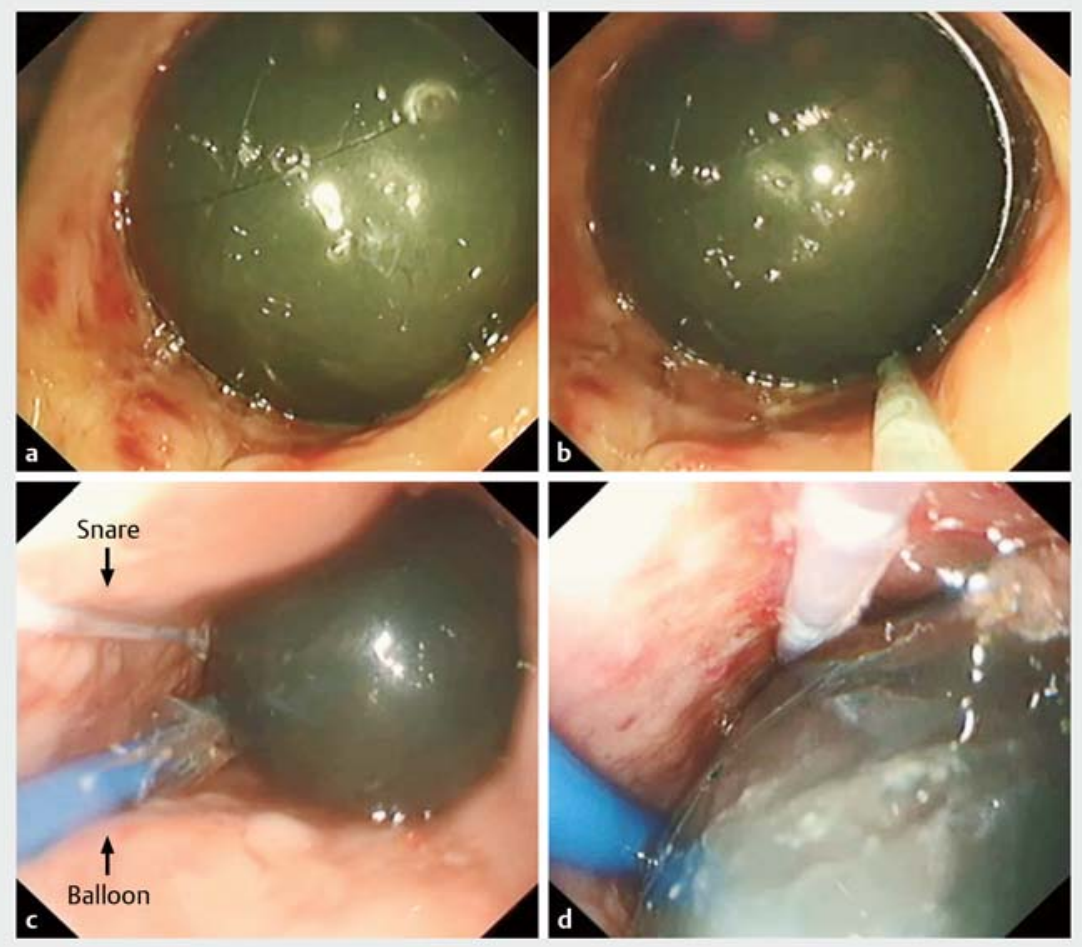

- Fig. 1 Images during proctosigmoidoscopy showing: a a lamp bulb wrapped with black tape at the rectosigmoid junction; $\mathbf{b}$ the bulb being grasped with a snare; $\mathbf{c}$ a balloon being passed along a guidewire alongside the bulb; $\mathbf{d}$ the snare and balloon being pulled outward at the same time.
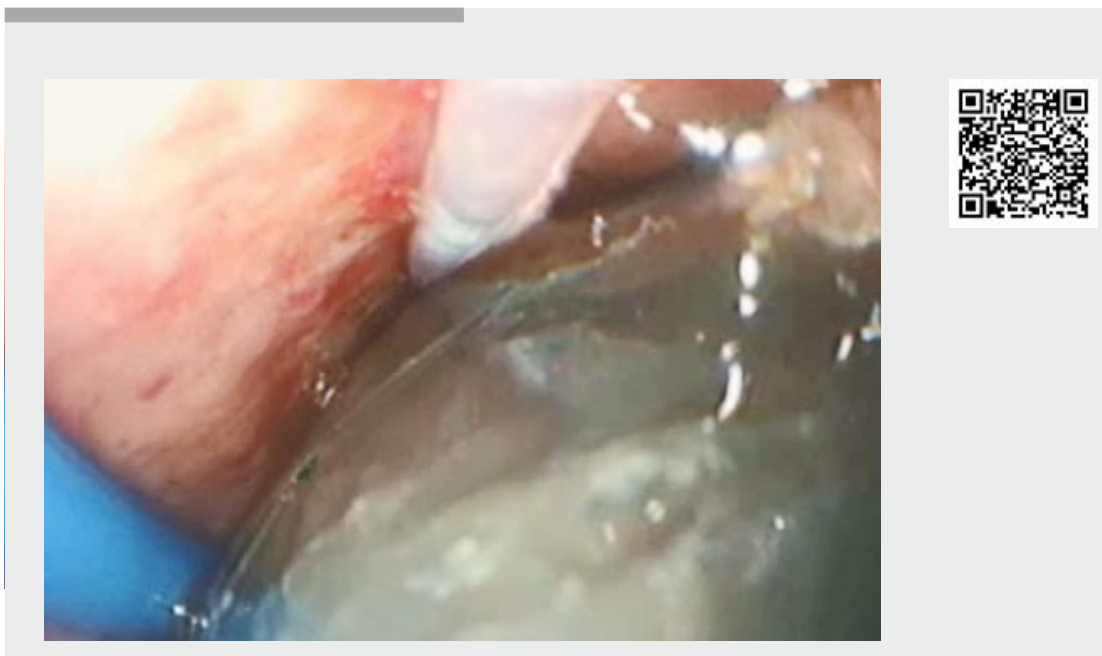

Video 1 Endoscopic extraction of a lamp bulb that was stuck at the rectosigmoid junction.
A 35-year-old man was referred to our hospital owing to insertion of a lamp bulb into his anus 5 hours earlier. The patient's abdomen was soft and not distensible. An abdominal radiograph showed a spherical opaque foreign body at the junction of the rectum and sigmoid, without any signs of perforation. Proctosigmoidoscopy found a black spherical foreign body $(5.0 \mathrm{~cm}$ in transverse diameter) at about $15 \mathrm{~cm}$ from the anus ( Fig.1a), which was wrapped with black tape and whose neck pointed to the oral side. Several attempts were made to remove it with a snare grasping

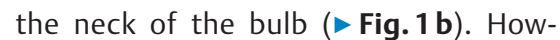
ever, the bulb rotated with endoscopic extraction and could not be passed through the acute angle of the rectosigmoid junction. Subsequently, a balloon was delivered over the bulb along a guidewire ( $\triangleright$ Fig. $1 \mathbf{c}$ ). After inflation of the balloon, the snare and the balloon were pulled outward at the same time ( $\vee$ Fig. 1 d; $\triangleright$ Video 1). Finally, the bulb was extracted successfully with withdrawal of the scope ( $\nabla$ Fig. 2 ). There were no additional injuries, and the patient was discharged uneventfully the same day.

Rectal foreign body is a unique part of colorectal trauma. It is very common nowadays and usually causes difficulties in extraction because of the delay in attending hospital while several attempts

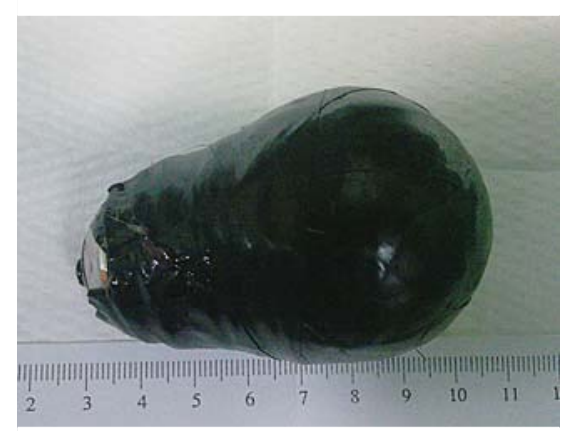

- Fig. 2 The lamp bulb after it had been removed. 
are made to extract it at home [1]. For high-lying foreign bodies, like the one described above, they are usually located near the rectosigmoid junction and a proctosigmoidoscopic procedure is always necessary [2,3]. Our experience in extracting foreign bodies stuck at the rectosigmoid junction suggests that the use of a snare and a balloon at the same time is helpful in fixing the rotatory foreign body, which then makes it easier to extract a difficult object such as this.

Endoscopy_UCTN_Code_TTT_1AQ_2AH

Acknowledgment

We acknowledge the support from National Key R\&D Program of China (Grant No. 2017YFC0112300 and 2017YFC0112305).

Competing interests

None
The authors

Zhe Feng", Zi-ming Liu ", Lian-song Ye, Wenjuan Yang, Lin-jie Guo, Jing Li, Bing Hu

Department of Gastroenterology, West China

Hospital, Sichuan University, Chengdu, China

\section{Corresponding author}

\section{Bing Hu, MD}

No. 37, Guo Xue Xiang, Wu Hou District, Cheng Du City, Sichuan Province, 610041, China

Fax: +86-028-85423387

hubingnj@163.com

\section{References}

[1] Coskun A, Erkan N, Yakan S et al. Management of rectal foreign bodies. World J Emerg Surg 2013; 8: 11

[2] Lyons MF, Tsuchida AM. Foreign bodies of the gastrointestinal tract. Med Clin North Am 1993; 77: 1101-1114

[3] Cologne KG, Ault GT. Rectal foreign bodies: what is the current standard? Clin Colon Rectal Surg 2012; 25: 214-218

\footnotetext{
* Equal first authors
}

Bibliography

DOI https://doi.org/10.1055/a-1022-4387

Published online: 25.10.2019

Endoscopy 2020; 52: E124-E125

(C) Georg Thieme Verlag KG

Stuttgart · New York

ISSN 0013-726X

\section{ENDOSCOPY E-VIDEOS}

https://eref.thieme.de/e-videos

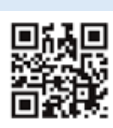

Endoscopy E-Videos is a free access online section, reporting on interesting cases and new

techniques in gastroenterological endoscopy. All papers include a high quality video and all contributions are freely accessible online.

This section has its own submission website at https://mc.manuscriptcentral.com/e-videos 